\title{
ОСОБЕННОСТИ КЛАСТОГЕНЕЗА В КАРБОНАТНЫХ ПОРОДАХ НИЖНЕГО ПАЛЕОЗОЯ СЕВЕРНОЙ ПРИБАЛТИКИ
}

Терригенный материал, устанавливаемый в карбонатных породах в виде нерастворимого остатка, представлял интерес для исследователей карбонатных пород Эстонии уже в прошлом веке. Химический состав нерастворимого остатка изучал впервые в Прибалтике по просьбе геолога А. Шренка (Schrenk, 1854) профессор химии Тартуского университета К. Шмидт. Важность систематического изучения терригенного компонента карбонатных пород для палеогеографических реконструкций показал А. Гэбель (Goebel, 1854). Однако он подчеркнул лишь значение относительного количества механической примеси, распределение которой по площади, по его мнению, позволяет восстановить конфигурацию бывшего берега, направление ветров, а также степень доломитизации.

Немного позже проблемой связи терригенного компонента с доломитизацией пород занимался А. Купфер (Kupffer, 1870), систематически изучавший химический состав карбонатных пород Эстонии и определивший таким путем количество нерастворимого остатка пород по разным горизонтам. Начатые в Эстонии в середине 19 в. работы по изучению карбонатных пород, в том числе их терригенного компонента, представляют несомненный интерес и с точки зрения истории науки, поскольку первые попытки исследования терригенного компонента карбонатных пород в некоторых других регионах мира, например в Америке, были сделаны значительно позже (Wethered, 1888). K сожалению, проведенные А. Шренком, А. Гэбелем и А. Купфером исследования карбонатных пород Эстонии были продолжены лишь полвека позже - в 30-е годы настоящего столетия (Orviku, 1940; Rosenstein, 1938, 1940).

Систематическое исследование терригенного материала палеозойских карбонатных пород Эстонии началось в начале 60-х годов, причем отдельно рассматривались минералы песчано-алевритовой и глинистой фракций. Обобщением этих материалов, с точки зрения сравнения их с результатами изучения минералов собственно терригенных пород, служит данная статья.

Основные особенности исследования терригенного материала карбонатных пород - это, во-первых, трудоемкость процесса его выделения (растворение, фракционирование), во-вторых, тонкозернистость и связанная с ней сложность минералогического определения. Мы сосредоточили внимание в первую очередь на исследовании песчано-алевритовой фракции, хотя ее количество в нерастворимом остатке, за исключением некоторых горизонтов нижнего и верхнего ордовика и верхнего силура, в среднем составляет $10-20 \%$, причем преобладает глинистый и тонкоалевритовый материал.

В первую очередь возникает вопрос об информативности этого материала. Ясно, например, что тонкозернистость материала не способствует выделению минералов тяжелой фракции; а также диагностике и изучению типоморфизма минералов, особенно тяжелых прозрачных. Однако 
терригенный компонент карбонатных пород служйт ценным коррелятивом, позволяющим сопоставить разнофациальные породы и проследить отложения от мелководных более чистых карбонатных, сформировавшихся в северной части Прибалтийского бассейна, до глинисто-карбонатных и глинистых, образовавшихся в более южной части бассейна. В более глубоководных участках бассейна карбонатонакопление имело подчиненное значение, ввиду чего литогенетические исследования соответствующих пород требуют другого подхода. Чтобы сравнить между собой карбонатные и глинистые породы, необходимо иметь определенные показатели по всему бассейну. Общим для всех типов пород компонентом является нерастворимый остаток, присутствующий как в мелководных известняках и доломитах, так и в мергелях, глинах и граптолитовых аргиллитах. Оставив в стороне встречающиеся в нерастворимом остатке аутигенные минералы, в информативности которых у нас не было сомнения, основное внимание мы сконцентрировали на минеральном составе терригенного, т. е. кластогенного материала.

Ниже остановимся на некоторых особенностях состава и распределения кластогенного материала нижнепалеозойских карбонатных пород Северной Прибалтики. Состав глинистых минералов детально рассматривать не будем, так как это сделано уже раньше (Юргенсон, 1978).

\section{Гранулометрические и морфологические осөбенности}

Как отмечено выше, содержание песчано-алевритовой фракции в терригенном материале незначительно. Исключение составляют некоторые интервалы карбонатных толщ онтикаского яруса, поркуниского горизонта и охесаареского горизонта, где рядом с известняками встречаются прослои известкового алевролита и песчаника. Гранулометрический состав терригенного материала тесно связан с его минералогией. Қак правило, минералы легкой фракции крупнее минералов тяжелой фракции. У легких минералов диаметр кварцевых зерен обычно больше, чем диаметр полевых шпатов, поэтому иногда преобладание полевых шпатов в терригенном материале объясняется его тонкозернистостью. Для выяснения гранулометрии основных компонентов тяжелой фракции проведены измерения под микроскопом максимального диаметра зерен циркона, граната, турмалина и рутила в 23 образцах. Оказалось, что средний, медиальный диаметр у циркона колеблется от 0,03 до 0,05 , у граната - от 0,038 до 0,080 , у турмалина - от 0,035 до 0,070 и у рутила — от 0,027 до 0,055 мм. Из этого следует, что минералогический анализ терригенного материала карбонатных пород необходимо провести для всей алевритовой фракции, не ограничиваясь только ее крупноалевритовой частью.

Сведений о морфологических особенностях терригенного материала пока еще мало. Соответствующие наблюдения проведены 'в целях выяснения влияния карбонатной среды на накопление и дальнейшее сохранение терригенного материала, в частности минералов легкой фракции кварца и полевых шпатов. Следы коррозии на зернах кварца чаще всего встречаются в терригенном материале известняков, образовавшихся в относительно мелководной, но спокойной среде. Терригенного материала в таких породах немного (3-10\%), известковый материал в них тонкозернистый и содержит часто остатки известковых водорослей. Нередко отмечается повышенное количество аутигенного кремнезема - главным образом в виде халцедона. Следы коррозии на кварце могли образоваться в основном на стадии диагенеза. Об этом свидетельствуют контакты кварца и карбонатного материала в шлифах. В разрезе силура отмечаются, например, два уровня, где корродированные зерна кварца широко распространены - это в среднем лландовери (райккюлаский 
горизонт) и в даунтоне (курессаареский и каугатумаский горизонты). В этих же слоях найдены и аутигенные кристаллики кварца.

Следы хлоритизации на зернах кварца, а также полевых шпатов распространены гораздо шире, чем следы коррозии. В противоположность последним хлоритизация связана преимущественно с терригенным материалом более глинистых известняков, а также мергелей и домеритов. Зерна полевых шпатов (ортоклаз, санидин) со следами растворения встречаются в известняках тех же горизонтов, в которых были найдены и корродированные зерна кварца. Кроме того, они отмечены и в верхнем венлоке (роотсикюлаский горизонт) и лудлове (паадлаский горизонт) в некоторых глинистых доломитах и доломитизированных известняках, накопление материала которых шло в мелководных застойных условиях. Процесс растворения внутри кристалла был иногда столь интенсивным, что сохранилась лишь его внешняя часть. Хотя явных доказательств по шлифам нет, можно предположить, что и растворение полевых шпатов произошло на стадии диагенеза. Гораздо сложнее объяснить образование регенерационных каемок вокруг зерен полевых шпатов, различная морфология которых указывает, по-видимому, на их разновозрастность. Каемки, имевшие ярковыраженную форму, могли образоваться в начальную эпоху диагенеза. Зерна с окатанными каемками происходят, наверное, из материнской породы. Следует отметить, что каемки с признаками явной окатанности типичны для зерен полевых шпатов терригенных пород.

Следы растворения отмечены также на зернах тяжелых минералов циркона, граната, редко - турмалина. Чаще всего они наблюдаются на тех же уровнях, где на зернах кварца и полевых шпатов встречались явные следы коррозии.

\section{Особенности минерального состава}

Минеральный состав терригенного материала карбонатных пород не отличается резко от состава выше- и нижележащих терригенных пород. Наиболее общей отличительной чертой его является несколько большее содержание малоустойчивых аллотигенных и обилие аутигенных минералов. Легкие минералы представлены в нерастворимом остатке кварцем, полевыми шпатами, мусковитом, хлоритом, биотитом, глауконитом, халцедоном, опалом; тяжелые - цирконом, гранатом, турмалином, титанистыми минералами (рутилом, анатазом, брукитом, титанитом, лейкоксеном), амфиболами и пироксенами, апатитом, корундом, эпидотом, ставролитом, дистеном, монацитом, силлиманитом, баритом, флюоритом, гидроокисями, окисями, сульфидами железа и т. д. Большинство их можно считать кластогенными в более узком смысле, исходными породами которых могли быть как осадочные (по всей вероятности, кембрийского или вендского возраста), так и магматические или метаморфические породы. В пользу первых говорит совершенная окатанность и небольшой диаметр зерен, небольшое число видов тяжелых минералов и преобладание среди них наиболее устойчивых. В пользу происхождения из метаморфических пород говорит довольно значительное содержание в некоторых горизонтах зерен кварца со следами динамометаморфизма, а также таких минералов, как дистен, силлиманит, ставролит и корунд. Особенно ощутимо влияние метаморфических пород в терригенном материале ордовика в северной части Палеобалтийского бассейна (Вингисаар и др., 1977) * и силура в северной и северо-западной части его.

* Вингис а ар П. А., Т а алман В. А., Кийпли Т. К., Гулова Х. С., Мурни к о в а Т. И. Отчет об изучении доломитизации в связи с комплексной оценкой месторождений карбонатного сырья, фосфоритов и горючих сланцев за 1973-1977 гг. Рукопись в ЭГФ, 1977. 
Ассоциация тяжелых аллотигенных минералов карбонатных пород иногда существенно отличается от соответствующей ассоциации терригенных отложений. Симптоматическим кластогенным минералом нерастворимого остатка карбонатных пород, присутствующим в них иногда в значительном количестве (до $50 \%$ и более от прозрачных аллотигенных тяжелых минералов), служит корунд. Он приурочен к наиболее крупнозернистой гранулометрической фракции. Концентрацию этого минерала, характерного для малораспространенных метаморфических исходных пород, в карбонатных отложениях можно, вероятно, объяснить специфическими условиями накопления, а также консервацией его в карбонатной среде.

Как уже отмечалось выше, небольшая часть обычно терригенных минералов может оказаться аутигенной. Встречаются аутигенный кварц, полевые шпаты, апатит, а возможны также титанистые минералы. В то же время часть аутигенных минералов не находится в данной породе in situ, а имеет явные признаки перемещения. Из таких минералов можно назвать барит, глауконит и флюорит. Так, например, флюорит в верхнем ордовике сбычно окатанный, привнесенный, и только в самом верхнем горизонте (поркуниском) аутигенный (Вийдинг, Ораспыльд, 1972, 1978).

Особое место в кластогенном материале карбонатных пород ордовика и силура занимают пирокластические минералы. Присутствие их в варьирующемся количестве - одна из основных отличительных особенностей кластогенеза в карбонатных породах, чего нельзя сказать о терригенных, накопление которых характеризуется значительно быстрыми темпами. Пирокластические минералы обнаружены рядом с терригенными в более значительных количествах от идавереского горизонта среднего ордовика до конца венлока в силуре. В более чистом виде сконцентрирован вулканический материал в метабентонитовых прослоях, мощность которых обычно колеблется в пределах нескольких сантиметров. Метабентониты сложены преимущественно глинистыми минералами (иллитом, смешанослойным монтмориллонит-иллитом, каолинитом) (Утсал, Юргенсон, 1971). В шлифах обнаруживается реликтовая витрокластическая структура. Характерными пирокластическими минералами в алевритовой фракции являются: прозрачная разновидность калиевого полевого шпата - санидин, клиновидные зерна кварца, шестигранные темно-коричневые чешуйки биотита, идиоморфные кристаллы циркона и апатита, а иногда также оскольчатые зерна граната, разнообразные (часто оскольчатые) зерна халцедона (иногда с пузырьками газа). Следует отметить, что нам пока не удалось найти осколков вулканического стекла, описанного П. Вингисааром и Т. Мурниковой (1973) в пирокластическом материале ордовика. Есть основание сомневаться в возможности сохранения фазы стекла в течение сотен миллионов лет.

Почти все перечисленные выше пирокластические минералы в небольшом количестве могут присутствовать рядом с обычными терригенными минералами в нерастворимом остатке карбонатных пород, как и терригенные минералы иногда присутствуют в метабентонитовых прослоях. Особенно часто наблюдаются пирокластические полевые шпаты, циркон и биотит. Предполагается, что поступление вулканогенного материала в карбонатный осадок в ходе сноса соседних регионов было почти непрерывным, но в зависимости от интенсивности извержений его количество то уменьшалось, то увеличивалось. Надо отметить, что влияние вулканизма в ордовике и силуре не ограничивалось только привносом пирокластического материала в виде взвеси, а выражалось также в изменении химизма среды. В периоды сильных вулканических извержений увеличивалось содержание калия и кремня в воде, что способствовало процессам аутигенеза в осадке. Метабентонитовые прослои были источником кремнезема и на стадиях диа- и катагенеза. 


\section{Особенности распределения терригенного материала}

Проведенные нами исследования показали, что многие события, сопровождающие осадконакопление карбонатных пород, нашли отражение в содержании и составе терригенного материала. Более значительные изменения в составе терригенного материала могут иметь и литостратиграфическое значение. Выяснилось, что выдержанный состав терригенного материала в каком-то промежутке времени позволяет расчленить разрез на отдельные комплексы пород, границы которых часто совпадают с праницами стратиграфических единиц, выделенных по фауне или по другим литологическим признакам (Юргенсон, 1977).

Наряду с эволюцией минерального состава терригенного материала по мере углубления эрозионного среза или перемещения областей питания, изменения тектонической активности или климата региона, довольно большую роль в распределении играла фациальная дифференциация в бассейне осадконакопления. Проведенные нами исследования показали, что средние содержания отдельных компонентов терригенного материала по литологическим типам карбонатно-глинистых пород без учета их фациальности довольно близки (Юргенсон, 1970). Можно отметить тенденцию уменьшения содержания песчано-алевритовой фракции от чистых известняков и доломитов к глинистым мергелям и глинам (от 20 до $8 \%$ ). Соотношение кварца и полевых шпатов уменьшается в противоположную сторону (от 2,0 в глинах до 3,4 в известняках). Общее содер-

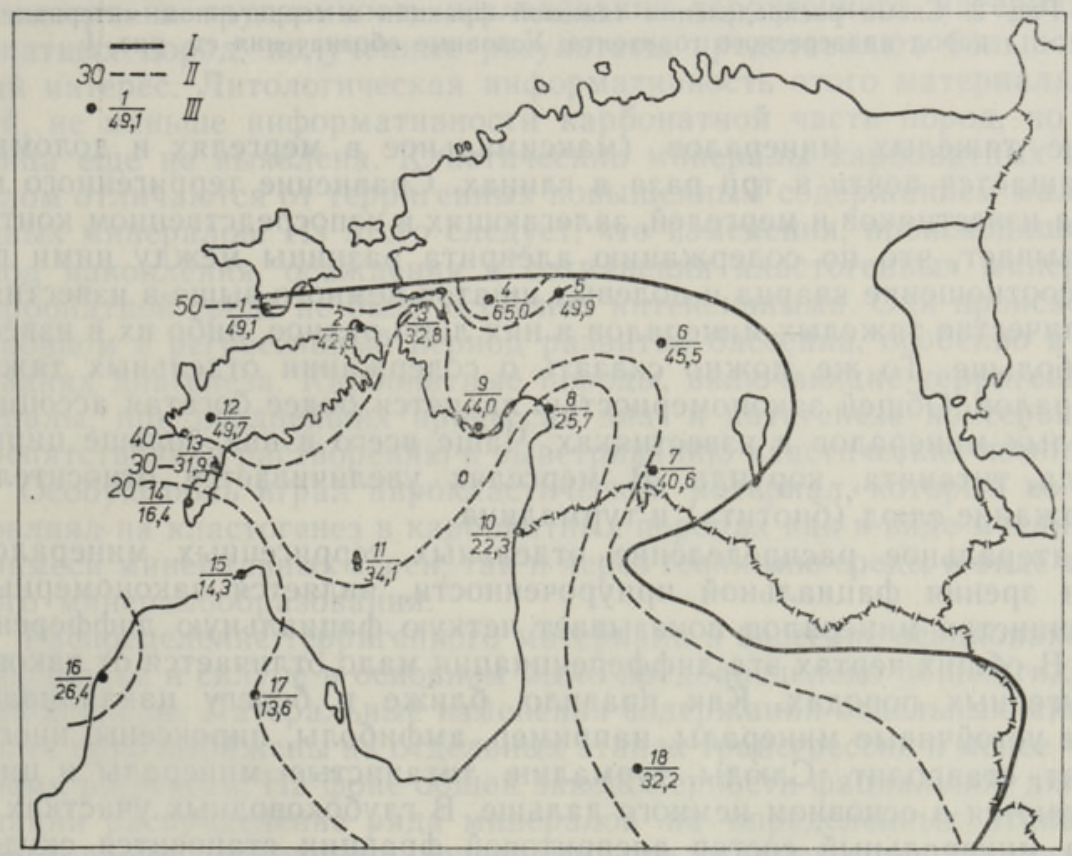

Рис. 1. Схема распределения полевых шпатов в легкой фракции терригенного материала пород адавереского горизонта (нижний силур) в Северной части Палеобалтийского бассейна. I - граница современного распространения адавереских отложений, II - изолинии среднего содержания полевых шпатов в легкой фракции терригенного матернала (цифрами указаны процентные содержания), III - номер буровой скважины (числитель) и среднее содержание в разрезе (знаменатель). Скважины: 1 - Эммасте, 2 - Муху, 3 - Кирикукюла, 4 - Румба, 5 - Нурме, 6 - Соомевере, 7 - Абъя, 8 - Пярну, 9 - Селисте, 10 - Икла, 11 - Рухну, 12 - Вики, 13 - Каугатума, 14 - Oхесааре, 15 - Колка, 16 - Вентспилс, 17 - Талсы, 18 - Нитауре. 


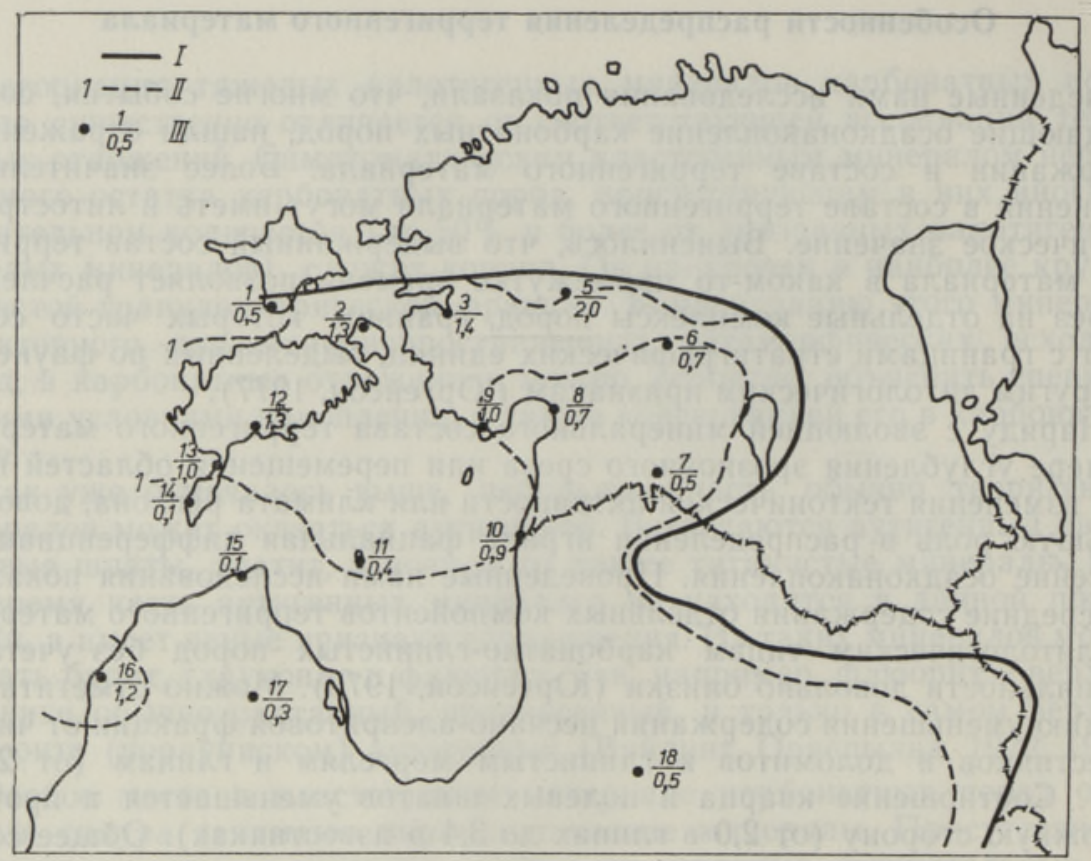

Рис. 2. Схема распределения тяжелой фракции в терригенном материале пород адавереского горизонта. Условные обозначения см. рис. 1.

жание тяжелых минералов (максимальное в мергелях и доломитах) сокращается почти в три раза в глинах. Сравнение терригенного материала известняков и мергелей, залегающих в непосредственном контакте, показывает, что по содержанию алеврита разницы между ними почти нет; соотношение кварца и полевых шпатов немного выше в известняках, а количество тяжелых минералов в них либо равное, либо их в известняках больше. То же можно сказать о содержании отдельных тяжелых минералов. Общей закономерностью является более богатая ассоциация тяжелых минералов в известняках. Чаще всего в них больше циркона, рутила, титанита, корунда. В мергелях увеличивается относительное содержание слюд (биотита) и турмалина.

Латеральное распределение отдельных терригенных минералов, с точки зрения фациальной приуроченности, является закономерным и большинство минералов показывает четкую фациальную дифференциацию. В общих чертах эта дифференциация мало отличается от таковой в терригенных породах. Как правило, ближе к берегу накапливаются менее устойчивые минералы, например, амфиболы, пироксены, иногда и гранат, ставролит. Слю́ды, турмалин, титанистые минералы и циркон отлагаются в основном немного дальше. В глубоководных участках бассейна минеральный состав алевритовой фракции становится скудным. Особую роль в карбонатных фациях играют органогенные постройки: рифы, биостромы, банки. Они препятствуют перемещению терригенного материала.

Распределение отдельных минералов тяжелой фракции по фациям может изменяться со временем. Например, в ордовике циркон, эпидот и пироксен больше всего тяготеют к мелководным фациальным зонам, в то время как гранат и корунд приурочены обычно к более глубоководным фациальным зонам в южной части бассейна. В распределении кварца и полевых шпатов в ордовике четкой закономерности пока не установлено, 
Иная картина распределения терригенных минералов наблюдается в силуре. Содержание полевых шпатов здесь постепенно уменьшается в сторону более глубоководных зон на всех этапах развития бассейна (рис. 1). Особенно четко проявляется эта закономерность во время позднелландоверийской трансгрессии. Аналогичная тенденция установлена в распределении тяжелой фракции в целом (рис. 2). Что касается изменений содержания граната и циркона, то здесь (по сравнению с ордовиком) картина немного сложнее. То же можно сказать о распределении турмалина. Максимальное содержание титанистых минералов связано с переходной зоной, с комковатыми известняками и мергелями. Некоторые минералы; как ставролит, дистен, эпидот и другие появляются только кратковременно, в основном в связи с трансгрессиями и в незначительных количествах, не обнаруживая особых закономерностей в распределении. Такие минералы, как корунд, амфиболы, пироксены и топаз, больше всего связаны с подводными течениями. Особенно это касается корунда, скапливающегося максимально в верхнем венлоке и в лудлове узкой полосой в северо-западной части бассейна. Ограниченное распространение он имеет и в нижней и средней лландовери в северовосточной части бассейна. Узким ареалом характеризуется также распространение амфиболов и пироксенов в ордовике в северо-восточной части бассейна.

\section{Выводы}

Несмотря на трудоемкость исследования терригенного материала карбонатных пород, полученные результаты представляют большой научный интерес. Литологическая информативность этого материала, пожалуй, не меньше информативности карбонатной части пород, но она до конца еще не выявлена. Кластические минералы карбонатных пород в целом отличаются от терригенных повышенным содержанием малоустойчивых минералов. Из этого следует, что изменения, происходящие в период накопления, осаждения и сохранения кластогенных минералов в карбонатной среде не были особенно интенсивными. Они происходили в основном в регрессивный период развития бассейна, особенно в ранних стадиях диагенеза. Карбонатные породы, включающие терригенные минералы, при позднейших процессах диа- и катагенеза консервировали, препятствовали растворению и выветриванию кластических компонентов.

Особую роль играл пирокластический материал, который во многом повлиял на кластогенез в карбонатных породах как в виде механической примеси минеральных зерен, так и через геохимию среды в виде аутигенного минералообразования.

Распределение терригенного материала в бассейне осадконакопления в ордовике и силуре в основном было предопределено общей гидродинамикой среды. Латеральные изменения содержаний отдельных минералов более ярко выражены на отдельных этапах трансгрессии и менее четко во время регрессии. На фоне общей закономерности фациальной дифференциации распределение ряда минералов на определенных этапах явно обусловлено придонными течениями, что указывает на гидродинамику бассейна. Более резкие изменения в составе минеральных ассоциаций терригенного материала обычно совпадают с изменениями в ходе эволющии седиментационного бассейна. Эти данные могут служить одним из критериев выделения литостратиграфических границ в разрезе древнепалеозойских карбонатных пород Прибалтики. 
$\mathrm{B}$ и йд и н г $\mathrm{X}$., О p a сп ыльд А. Литология и минералогия камарикуской пачки поркуниского горизонта. - Изв. АН ЭССР. Хим., Геол., 1972, 21, 243-258.

$\mathrm{B}$ и й д и н $\mathrm{r} \mathrm{X}$., $\mathrm{O}$ р а с п ы ль д А. О литологин и минералогии салдусской свиты ( $\left.\mathrm{F}_{\mathrm{II}} \mathrm{S}\right)$ в средней части Прибалтики. - Изв. АН ЭССР. Геөл., 1978, 27, 119-129.

В и нги с а а р П., Мурников а Т. Новые данные о минералогин некоторых нижнекарадокских метабентонитов Эстонии. - Изв. АН ЭССР. Хим., Геол., 1973, 22, $149-157$.

У т с а К., Юрге н сон Э. Минералогия метабентонитов Эстонии. - Изв. АН ЭССР. Хим., Геол., $1971,20,336-348$.

Ю р ген сон Э. Распределение и состав терригенного материала. - В кн.: Силур Эстонии. Таллин, 1970, 68-96.

Юрген сон Э. Расчленение разрезов силурийских отложений Прибалтики по терригенному материалу. - В кн.: Фации и фауна силура Прибалтики. Таллин, 1977, 56-70.

Юргенсон Э. Распределение глинистых минералов в силурийских породах Северной Прибалтики. - Изв. АН ЭССР. Геол., 1978, 27, 79-87.

Go ebel, A. Uber das Bedingende der Färbung in den grauen und gelben Dolomiten und Kalksteinen der obern silurischen Gesteingruppe Liv- und Ehstlands. - Arch. Naturk. Liv-, Ehst- und Kurlands, Ser. 1, 1, L. 1, Dorpat, $1854,239-286$.

Kupffer, A. Ober die chemische Constitution der baltisch-silurischen Schichten. Arch. Naturk. Liv- und Ehst- und Kurlands, Ser. 1, V, Dorpat, 1870, 69-194.

Orviku, K. Lithologie der Tallinna-Serie (Ordovizium, Estland). I. Tartu, 1940.

Rosenstein, E. Borealis-lubjakivid Tamsalu-Rakke vahelises lubjatööstusrajoonis. - Eesti Loodus, 1938, 4, 162-168.

Rosenstein, E. Raikküla lade Tamsalu-Paide vahelisel alal. - Eesti Loodus, 1940, $2,94-102$.

Schrenk, A. Obersicht des oberen silurischen Schichtensystems Liv- und Ehstlands, vornämlich ihrer Inselgruppe. - Arch. Naturk. Liv-, Ehst- und Kurlands, Ser. 1, 1, L. 1, Dorpat, 1854.

Wethered, E. On insoluble residues. - Geological Magazine, Decade III, 1888, 5,139 .
Институт геологии
Академии наук Эстонской ССР
Поступила в редакцию
$20 / \mathrm{I} 1982$

\section{Erika JORGENSON, H. VIIDING \\ PÖHJA-BALTIKUMI ALAMPALEOSOIKUMI KARBONAATKIVIMITE KLASTOGENEESI ISEARASUSED}

Ordoviitsiumi ja siluri karbonaatkivimite lahutusjäägi analüüsi alusel on kirjeldatud terrigeensete mineraalide granulomeetriat, mineraalset koostist, terakeste morfoloogiat ning mineraalikoosluste jaotust läbilōikes ja fatsiaalsetes vöötmetes. Tuuakse esile klastogeneesi peamised iseärasused karbonaatkivimites terrigeensetega võrreldes. Need avalduvad peamiste purdmineraalide (kvarts, päevakivi, vilgud) suhteliselt väiksemates môōtmetes, nende sagedamates korrosioonijälgedes, vulkanoklastiliste mineraalide (kaltsedon, sanidiin jt.) kohati märkimisväärses osas ning suuremas vähempüsivate (epidoot, amfiboolid, pürokseenid) ja mõnede sümptomaatiliste mineraalide (korund, topaas, glaukoniit, fluoriit jt.) sisalduses. Mineraalide horisontaaljaotuses on etendanud määravat osa basseini hüdrodünaamika, vẹrtịkạalsẹs aga sellelę lisạks lähtealade ișeloomu, țektọonika ja kliima muutus. 


\section{THE PECULIARITIES OF CLASTOGENESIS IN THE NORTH-BALTIC EARLY PALAEOZOIC CARBONATE ROCKS}

The present work is an attempt to clarify the behaviour of the terrigenous material in carbonate rocks. The content of insoluble residue in the Ordovician and Silurian carbonate rocks of Estonia varies greatly. It is represented by fine-grained pelitic material containing silt fraction, in most cases, less than 20 per cent. According to the latter, the mineralogical analysis of all the silt fraction was carried out. There are no fundamental differences between the mineral associations of the clastic material of Ordovician and Silurian carbonate rocks and the adjacent terrigenous rocks (Cambrian and Devonian). In the light mineral fraction quartz and feldspars are present. The mica group contains biotite, muscovite and chlorite. The transparent non-micaceous heavies are represented by zircon, garnet, tourmaline, and $\mathrm{Ti}$ minerals. Sometimes a large quantity of corundum was found, most likely brought by bottom currents. In many cases, especially in Ordovician rocks, there is an admixture of pyroclastic material.

The state of preservation of the terrigenous minerals in carbonate rocks is good. Such unstable minerals as amphiboles and pyroxenes are better preserved than in terrigenous rocks. Mineral grains with visible signs of solution were found mainly in rocks of the regressive sedimentation phase. The influence of pyroclastic material on the authigenous mineral-forming process is not negligible.

The number and the content of terrigenous minerals varies in the investigated rocks laterally as well as vertically due to the general evolution of the OrdovicianSilurian sedimentary basin and its facial zonality (Figs 1,2). The variability of the terrigenous minerals makes them suitable for use at palaeogeographical reconstruction and for establishing lithostratigraphical boundaries. 